\title{
PENERAPAN MANAJEMEN SAINS PADA ORGANISASI
}

\author{
Sarah Aulia \\ 175100053P \\ Fakultas Komputer \\ sarahaulia.student@umitra.ac.id
}

\begin{abstract}
Manajemen sains adalah ilmu yang mengajarkan kita bagaimana menerapkan ilmu sains dalam kegiatan manajemen,dan tentu dengan tujuan untuk mempermudah bisnis,meminimalisasi biaya yang harus di keluarkan dan meningkatkan keuntungan .
\end{abstract}

Sains Manajemen berfokus terutama pada pengembangan model matematika. Model matematika adalah representasi dari sebuah system, proses, atau hubungan yang disederhanakan.

Tujuan utama dari management sains adalah untuk menyelesaikan masalah-masalah yang dihadapi oleh seorang menager baik yang bergerak dalam sektor publik maupun swasta dalam proses pengambilan keputusan dengan cara pendekatan model-model matimatika.

Kata Kunci : Penyelesaian Masalah, Manajemen sains. 
A. PENDAHULUAN

Manajemen Sains adalah ilmu yang mengajarkan kita bagaimana menerapkan ilmu sains dalam kegiatan manajemen, tentu dengan tujuan untuk mempermudah bisnis, meminimalisasi biaya yang harus dikeluarkan dan meningkatkan keuntungan dengan menggunakan cara kerja berdasarkan prinsip prinsip keilmuan.

Pengertian lainnya yaitu Manajemen sains adalah cabang dari teknik yang disertakan dalam pembelajaran, bagaimana untuk melukiskan, menilai, mendesain, mengubah, mengontrol dan termasuk pelaksanaan dari system-sistem yang tergabung dari manusia, material-material, dan teknologi, dilihat dari waktu ke waktu dan dengan keadaan yang relavan.

Disinilah manajemen sains berperan yaitu dengan menerapkan pendekatan ilmiah untuk memecahkan masalahmasalah manajemen diatas dalam rangka membantu manajer mengambil keputusan yang paling tepat. Secara ringkas manajemen sains melakukan pendekatan dengan langkah-langkah sebagai berikut:

Melakukan pengamatan atau observasi
Mendefinisikan masalahmasalah yang ada

Membuat pemodelan pada masalah-masalah yang telah didefinisikan

Menentukan solusi model

Melaksanakan pemecahan model

Langkah-langkah Manajemen Sains:

Melakukan Observasi: Mengenali dan mempelajari masalah-masalah yang dialami organisasi atau perusahaan agar masalah tersebut dapat dikenali dan bisa diantisipasi sebelumnya.

Mendefinisikan Masalah: Masalah harus dapat didefinisikan dan dijabarkan dengan singkat, tepat dan jelas. Visi dan misi perusahaan akan sangat membantu dalam mengetahui masalah yang sedang terjadi.

Membuat Pemodelan: Suatu pemodelan secara manajemen sains yang tepat harus dibuat yang merupakan penyajian ringkas untuk menggambarkan masalah yang sedang dihadapi.

Menentukan Solusi: pemecahan masalah bisa dilakukan dengan program linear (metoda grafis, simpleks, transportasi, penugasan dan lain-lain), stokastik, probabilitas dan teknik jaringan lainnya (simulasi, peramalan, persediaan, analisis hierarki dan lain-lainnya.)

Melakukan perhitungan untuk mendapatkan solusi.

Ada kalanya satu model manajemen sains tidak 
memungkinkan mendapatkan solusi optimal, maka harus digunakan pemodelan yang lainnya agar benar-benar mendapatkan hasil yang optimal.

\section{B. PEMBAHASAN / STUDI KASUS}

Management Sains adalah suatu ilmu yang menggunakan aplikasi matematika dalam penyelesain masalah yang dihadapi seorang manager yang dijelaskan sebagai filosofi dan logika untuk melakukan pemecahan masalah tersebut.

Tujuan utama dari management sains adalah untuk menyelesaikan masalahmasalah yang dihadapi oleh seorang menager baik yang bergerak dalam sektor publik maupun swasta dalam proses pengambilan keputusan dengan cara pendekatan model-model matimatika.Management sains dapat dipergunakan pada berbagai organisasi untuk memecahkan berbagai macam masalah yang meliputi logika dalam pemecahan masalah. Pendekatan secara logis, konsisten, dan sistematis terhadap pemecahan masalah sangat berguna dan berharga sama dengan pengetahuan tentang teknik matematika itu sendiri. Akan tetapi management sains dalam perkuliahan saat ini menggunakan perangkat lunak seperti Microsoft Excel ,QM for windows sehingga tidak terlalu rumit untuk menyelesaikannya dengan menggunakan metode matematika biasa. Sebagian orang juga merasa kalau matematika itu menakutkan, namun matematika dalam manajemen sains tidaklah seperti matematika pada umumnya karena pendekatannya menggunakan perangkat lunak. Sesuai pengertian sebelumnya, sains management meliputi pendekatan sistematis dan logis dalam memecahakan masalah atau merupakan metode ilmiah untuk memecahkan masalah. Pendekatan ini harus mengikuti langkah-langkah teratur yang telah diterima secara umum:

1. Pengamatan (Observasi).

2. Defenisimasalah.

3. Perumusan model.

4. Pemecahan model.

5. Pelaksanaan (implementasi) hasil pemecahan model.

Untuk memudahkan kita memahami maksud dari langkah-langkah diatas kita bisa langsung membahas kepada management itu sendiri, dan kali ini saya akan coba membahas bab "transportasi, pengapalan, dan penugasan". dengan pernyataan masalah sebagai berikut :

Suatu perusahaan beton memindahkan beton dari tiga pabrik menuju ke tiga lokasi konstruksi, Kapasitas penawaran dari tiga pabrik, permintaan dari tiga lokasi, dan 
biaya transportasi per ton adalah sebagai berikut

\begin{tabular}{|l|l|l|l|l|}
\hline Pabrik & \multicolumn{3}{|l|}{$\begin{array}{l}\text { LokasiKonst } \\
\text { ruksi }\end{array}$} & $\begin{array}{l}\text { Penaw } \\
\text { aran } \\
\end{array}$ \\
\cline { 2 - 5 } & $\mathrm{A}$ & $\mathrm{B}$ & $\mathrm{C}$ & (ton) \\
\hline 1 & $\$ 8$ & 5 & 6 & $\$ 120$ \\
\hline 2 & 15 & 10 & 12 & 80 \\
\hline 3 & 3 & 9 & 10 & 80 \\
\hline $\begin{array}{l}\text { Permintaa } \\
\text { n(ton) }\end{array}$ & $\begin{array}{l}15 \\
0\end{array}$ & 70 & 60 & \\
\hline
\end{tabular}

Formulasi model program linear

Minimalkan

$\mathrm{Z}=$

$8 \times 1 a+5 \times 1 b+6 \times 1 c+15 \times 2 a+10$

$X 2 b+12 \times 2 c+3 \times 3 a+9 \times 3 b+10$

$\mathrm{X} 3 \mathrm{c}$

Batasan

$X 1 a+X 1 b+X 1 c=120$

$X 2 a+X 2 b+X 2 c=80$

$\mathrm{X} 3 \mathrm{a}+\mathrm{X} 3 \mathrm{~b}+\mathrm{X} 3 \mathrm{c}=80$

$X 1 a+X 2 a+X 3 a<=150$

$\mathrm{X} 1 \mathrm{~b}+\mathrm{X} 2 \mathrm{~b}+\mathrm{X} 3 \mathrm{~b}<=70$

$\mathrm{X} 1 \mathrm{c}+\mathrm{X} 2 \mathrm{c}+\mathrm{X} 3 \mathrm{c}<=100$

$\mathrm{Xij}=0$

Kita menggunakan Excel untuk pemecahan masalah:

Setelah kita solve dan melihat hasilnya (hasilnya yang terletak didalam lingkaran merah) kita dapat menentukan berapa yang harus dikirim dan diterima berdasarkan table tersebut.

Demikianlah implementasi management sains agar para menager dapat mengambil keputusan dalam menyelesaiakan masalah.
C. ID SECURITY

QWTD4452377-ASP-5244107

\section{KESIMPULAN}

Kemampuan manajemen waktu merujuk pada kemampuan seorang manajer untuk menggunakan waktu yang dimilikinya secara bijaksana dan umumnya organisasi berkinerja tinggi memiliki kamus kompetensi dan menerapkan kompetensi tersebut kepada hal-hal penting, seperti melakukan pengamatan(Observasi),

defenisimasalah, perumusan model, Pemecahan

model, Pelaksanaan

(implementasi)

hasil

pemecahan model.manajemen kinerja, serta seleksi rekruitmen, pendidikan, pengembangan, dan promosi. Jika kompetensi ini sudah dibakukan di dalam organisasi, maka kegiatan manajemen SDM akan menjadi lebih transparan, dan pimpinan organisasi juga dengan mudah mengetahui kompetensi apa saja yang perlu diperbaiki untuk membawa organisasi menjadi berkinerja tinggi.

Terdapat suatu gaya kepemimpinan (leadership style) yang mengarah kepada pembentukan organisasi berkinerja tinggi. Inti dari kepemimpinan seperti ini adalah adanya suatu proses coaching, counseling, dan empowerment kepada para bawahan atau sumber daya manusia di dalam organisasi. 
Satu aspek lain yang sangat penting dalam gaya kepemimpinan adalah, sikap followership, atau menjadi pengikut.

Bayangkan jika semua orang menjadi komandan di dalam organisasi, lantas siapakah yang menjadi pelaksana ? Bukannya kinerja tinggi yang muncul, melainkan kekacauan di dalam organsiasi (chaos). Sejatinya, pada kondisi tertentu seseorang harus memiliki jiwa kepemimpinan, tetapi pada situasi yang lain, dia juga harus memahami bahwa dia juga merupakan bagian dari sebuah sistem organisasi yang lebih besar, yang harus dia ikuti.

\section{E. DISKUSI}

Menerapkan manajemen pada suatu organisasi harus berkinerja tinggi memiliki kamus kompetensi dan menerapkan kompetensi tersebut kepada hal-hal penting, seperti melakukan

pengamatan(Observasi), defenisimasalah, perumusan model, Pemecahan

model, Pelaksanaan

(implementasi) hasil pemecahan model.manajemen kinerja, serta seleksi rekruitmen, pendidikan, pengembangan, dan promosi. Jika kompetensi ini sudah dibakukan di dalam organisasi, maka kegiatan manajemen SDM akan menjadi lebih transparan, dan pimpinan organisasi juga dengan mudah mengetahui kompetensi apa saja yang perlu diperbaiki untuk membawa organisasi menjadi berkinerja tinggi

Ingatlah pilar-pilar tinggi dalam manajemen unggul Perlunya perencanaan yang seksama, pertimbangan dan pengambilan keputusan yang sehat, implementasi dan pemantauan keputusan dan pengoperasian yang hati-hati dan kreatif, serta kepedulian terhadap karyawan dan hasilnya, yang didasarkan pada ketrampilan manajemen serta gaya manajemen kelas satu. Ketrampilan ini mencakup perencanaan, pengorganisasian, penyusunan staff, pembuatan keputusan, penganggaran, inovasi, komunikasi, representasi, pengendalian, pengarahan dan pemberian motivasi hubungan antar persona.

\section{F. REFERENCE}

[1] O. M. Febriani and A. S. Putra, "Sistem Informasi Monitoring Inventori Barang Pada Balai Riset Standardisasi Industri Bandar Lampung," J. Inform., vol. 13, no. 1, pp. 90-98, 2014.

[2] A. S. Putra, "Paperplain: Execution Fundamental Create Application With Borland Delphi 7.0 University Of Mitra Indonesia," 2018.

[3] A. S. Putra, "2018 Artikel Struktur Data, Audit Dan 
Jaringan Komputer," 2018.

A. S. Putra, "ALIAS

MANAGER USED IN

DATABASE DESKTOP

STUDI CASE DB DEMOS."

A. S. Putra, "COMPREHENSIVE SET OF PROFESSIONAL FOR DISTRIBUTE COMPUTING."

[6] A. S. Putra, "DATA ORIENTED RECOGNITION IN BORLAND DELPHI 7.0."

[7] A. S. Putra, "EMBARCADERO DELPHI XE 2 IN GPUPOWERED FIREMONKEY APPLICATION."

[8] A. S. Putra, "HAK ATAS KEKAYAAN INTELEKTUAL DALAM DUNIA TEKNOLOGY BERBASIS REVOLUSI INDUSTRI 4.0."

[9] A. S. Putra, "IMPLEMENTASI PERATURAN

PERUNDANGAN UU. NO 31

TAHUN 2000 TENTANG DESAIN INDUSTRI BERBASIS INFORMATION TECHNOLOGY."

[10] A. S. Putra, "IMPLEMENTATION OF PARADOX DBASE."

A. S. Putra, "IMPLEMENTATION OF TRADE SECRET CASE STUDY SAMSUNG MOBILE PHONE."

[12] A. S. Putra, "IMPLEMENTATION

PATENT FOR APPLICATION WEB BASED CASE STUDI WWW. PUBLIKLAMPUNG. COM."
IN DIGITALLY INDUSTRY."

[14] A. S. Putra, "MANUAL REPORT \& INTEGRATED DEVELOPMENT

ENVIRONMENT BORLAND DELPHI 7.0."

[15] A. S. Putra, "PATENT AS RELEVAN SUPPORT RESEARCH."

[16] A. S. Putra, "PATENT FOR RESEARCH STUDY CASE OF APPLE. Inc."

[17] A. S. Putra, "PATENT PROTECTION FOR APPLICATION INVENT."

[18] A. S. Putra, "QUICK REPORT IN PROPERTY PROGRAMMING."

[19] A. S. Putra, "REVIEW CIRCUIT LAYOUT COMPONENT

REQUIREMENT ON ASUS NOTEBOOK."

[20] A. S. Putra, "REVIEW TRADEMARK PATENT FOR INDUSTRIAL TECHNOLOGY BASED 4.0."

[21] A. S. Putra, "TOOLBAR COMPONENT PALLETTE IN OBJECT ORIENTED PROGRAMMING."

[22] A. S. Putra, "WORKING DIRECTORY SET FOR PARADOX 7."

[23] A. S. Putra, "ZQUERY CONNECTION

IMPLEMENTED

PROGRAMMING STUDI CASE PT. BANK BCA Tbk."

[24] A. S. Putra, D. R. Aryanti, and I. Hartati, "Metode SAW (Simple Additive Weighting) sebagai Sistem Pendukung Keputusan Guru Berprestasi (Studi Kasus: SMK Global 
Surya)," in Prosiding Seminar Nasional Darmajaya, 2018, vol. 1, no. 1, pp. 85-97.

[25] A. S. Putra and O. M. Febriani, "Knowledge Management Online Application in PDAM Lampung Province," in Prosiding International conference on Information Technology and Business (ICITB), 2018, pp. 181-187.

[26] A. S. Putra, O. M. Febriani, and B. Bachry, "Implementasi Genetic Fuzzy System Untuk Mengidentifikasi Hasil Curian Kendaraan Bermotor Di Polda Lampung," SIMADA (Jurnal Sist. Inf. dan Manaj. Basis Data), vol. 1, no. 1, pp. 21-30, 2018.

[27] A. S. Putra, H. Sukri, and K. Zuhri, "Sistem Monitoring Realtime Jaringan Irigasi Desa (JIDES) Dengan Konsep Jaringan Sensor Nirkabel," IJEIS (Indonesian J. Electron. Instrum. Syst., vol. 8, no. 2, pp. 221-232.

[28] D. P. Sari, O. M. Febriani, and A. S. Putra, "Perancangan Sistem Informasi SDM Berprestasi pada SD Global Surya," in Prosiding Seminar Nasional Darmajaya, 2018, vol. 1, no. 1, pp. 289-294. 